\title{
Effect of Cold Water Intake During Exercise in Heat on Cognitive Function
}

\author{
Yunbin Lee MS, Somi Yun PhD, Jaegu Hwang MS, Heejin Lee PhD, Ah Reum Jung PhD, Dae Taek Lee PhD \\ Department of Exercise Physiology Laboratory, Kookmin University, Seoul, Korea
}

PURPOSE: The purpose of this study was to examine the effect of cooling treatment by cold water intake before and during exercise in a hot environment on cognitive function.

METHODS: Twelve healthy adult men $\left(26.3 \pm 4.4\right.$ years, $\left.176.2 \pm 5.8 \mathrm{~cm}, 77.2 \pm 14.6 \mathrm{~kg}, 24.8 \pm 3.7 \mathrm{~kg} / \mathrm{m}^{2}\right)$ completed 3 exercise tests; with drinking warm water $\left(36.5^{\circ} \mathrm{C}\right)$, with drinking cold water $\left(4^{\circ} \mathrm{C}\right)$, or without drinking water. Each test was separated at least 3 days. During each test, they ran on a treadmill for 20 minutes at $75 \%$ of their maximal heart rate in $40^{\circ} \mathrm{C}$ with $40 \%$ of humidity. For the drinking conditions, the total volume of drinking was set to $1 \%$ of the participant's weight. Before the test in each drinking condition, they consume $1 / 3$ of the total volume at once. The remaining $2 / 3$ was consumed separately 3 times at six-min interval during exercise. A neuropsychological test using the Stroop Color and Word Test (SCWT) was conducted before and after the exercise to examine the changes of cognitive abilities. Data were analyzed using a two way repeated measures ANOVA.

RESULTS: Comparing pre- and post-exercise SCWT, the main effects in words, colors, and words and colors were noticed ( $p=.000$, $p=.003$, and $p=.008$, respectively). No differences were found between water drinking conditions.

CONCLUSIONS: Overall, a short bout of high-intensity exercise in the hot environment improved cognitive functions, but it was not possible to determine how water temperature and water intake affected cognitive ability. Further research is needed considering the ages and fitness levels of participants.

Key words: Stroop color and word test, Pre-cooling, High temperature exercise

\section{INTRODUCTION}

Regular exercise is recommended for most people to improve health, but participation to exercise is often hampered by environmental conditions [1]. In particular, exercise in hot environments increases the skin blood flow and sweating rate for regulation of body temperature leading to a body water depletion and an imbalance of body homeostasis [2]. The increased depletion of body water by sweating also decreases venous return inducing a cardiac performance drift limiting exercise capacities $[1,3]$. The elevation of body temperature and dehydration caused by heat exposure affect the normal body functioning and mood of the brain, which can adversely affect cognitive function $[4,5]$.
Cognitive function is considered a very important factor during exercises and performing sports which require physical skills and mental judgment. Cognitive function during exercise is known to be affected by dehydration, body temperature elevation, and hypoglycemia [6]. When the body becomes dehydrated for a long time or acutely, the blood flow to the cerebrovascular vessels decreases, and changes in electrolytes such as hypernatremia and hormonal changes such as glucocorticoid and vasopressin can negatively affect the physical function [7].

Cold treatments against body temperature elevation and dehydration is one of the strategy to prevent heat injuries and physical performance declines. Cold treatment refers to a method of cooling body such as drinking cold water, exposure to cold air, and/or wearing an ice vest be-

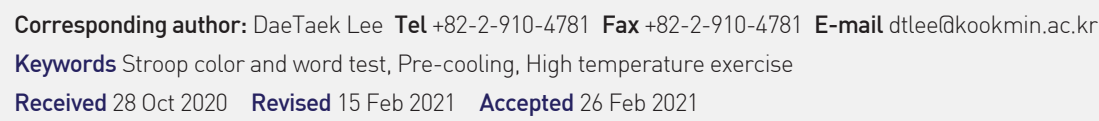


fore, during, and after exercises to leveling the negative effects of the heat stress [8-13]. Pre-cooling can also delay sweating and dehydration by lowering the body temperature before exercise and extend the time of initiation of temperature increment during exercise $[8,14,15]$. However, an application of external cooling methods to the human body requires facilities, equipments, and time for cooling. As the greater the cold stress, the greater the discomfort of the subject when using the external cooling $[16,17]$.

Complementing the shortcomings of the external cooling method of the human body and lowering the body temperature when exercising in a hot environment, 'cold water drinking before exercise' can be suggested as a simple cooling treatment method for gaining advantage. According to a previous study, a cold water drinking $\left(4^{\circ} \mathrm{C}\right)$ during exercise in a hot environment can play as a heat absorber, slowing the rise of the body temperature and reducing the levels of heat stress [18]. When the body temperature was decreased by $0.5^{\circ} \mathrm{C}$ after drinking $4^{\circ} \mathrm{C}$ water in a hot and humid environments, the heart rate was lower than after drinking $37^{\circ} \mathrm{C}$ water [19]. Cold water drinking before exercise reduced sweating [20] and had a positive effect on the ratings of perceived exertion and the thermal sensation [18].

When considering the facts that body temperature elevation and dehydration can adversely affect cognitive function, a proper cold water consumption in a hot environment not only prevents dehydration but also improves the exercise performance with affecting on cognitive function. However, most of the existing studies have focused on the effect of cold water intake on body temperature, and it is still unclear how it affects cognitive function. In addition, despite the fact that water temperature can affect the absorption rate of water in the body, most of the preceding studies have only been studied with a specific temperature, and the water temperature of ingested water has not been standardized [21-23]. Therefore, it is necessary to identify how important the variables related to the temperature of ingested water are for the cognitive function in a hot environment. The purpose of this study is to investigate the effect of water intake at various water temperatures before and during exercise on cognitive function in a hot environment.

\section{METHODS}

\section{Participants}

Twelve healthy young men with no known cardiovascular diseases and/or other illnesses were recruited as participants (Table 1). They re-
Table 1. Physical characteristics of the subjects

$(\mathrm{M} \pm \mathrm{SD})$

\begin{tabular}{lccccc}
\hline & $\begin{array}{c}\text { Age } \\
(\mathrm{yr})\end{array}$ & $\begin{array}{c}\text { Height } \\
(\mathrm{cm})\end{array}$ & $\begin{array}{c}\text { Weight } \\
(\mathrm{kg})\end{array}$ & $\begin{array}{c}\mathrm{BMl} \\
\left(\mathrm{kg} / \mathrm{m}^{2}\right)\end{array}$ & $\begin{array}{c}\text { BF } \\
(\%)\end{array}$ \\
\hline Man $(\mathrm{n}=12)$ & $26.3 \pm 4.4$ & $176.2 \pm 5.8$ & $77.2 \pm 14.6$ & $24.8 \pm 3.7$ & $22.2 \pm 5.3$ \\
\hline
\end{tabular}

Values are mean $\pm \mathrm{SD}$.

$\mathrm{BMI}$, body mass index; $\mathrm{BF}$, body fat content.

ceived an explanation of the purpose, procedures, and risks associated with the study and filled out the consent form for the study. The study was approved by the Institutional Research Ethics Committee and all research procedures were carried out in accordance with the Declaration of Helsinki and the Ethical Guidelines of the American College of Sports Medicine (ACSM).

\section{Experimental design}

Participants were randomly assigned and completed 3 test sessions; with dinking warm water $\left(36.5^{\circ} \mathrm{C}\right)$, with drinking cold water $\left(4^{\circ} \mathrm{C}\right)$, or without drinking water. In each session, they ran on a treadmill for 20 $\mathrm{min}$ at their $75 \%$ of maximal heart rate $(154.4 \pm 5.6,157.8 \pm 10.3,152.8 \pm$ $7.9 \mathrm{bpm}$ in cold water, warm water, and no water conditions, respectively) in $39.2 \pm 2.1^{\circ} \mathrm{C}$ and $41.4 \pm 8.6 \%$ of relatively heat environment.

The hydration group, in order to minimize the difference in the amount of dehydration, the individual's water intake and exercise intensity were managed to be the same. For the drinking conditions, the total volume of drinking was set to $1 \%$ of the participant's weight [19]. Before the test in each drinking condition, they consume $1 / 3$ of the total volume at once. The remaining 2/3 was consumed separately 3 times at sixmin interval during exercise. Before and after their exercise bouts, their cognitive function was tested using the Stroop Color and Word Test (SCWT) [25]. At rest and during exercise their heart rate by electronic monitor (H7 Bluetooth Heart Rate Sensor, Polar, Finland) and 3 skin temperatures (pectoral muscle, brachial triceps, and quadriceps) using thermocouples were monitored and recorded (Thermocouple Scanner, Barnant Company, USA). Tests were conducted at a same time of the day and each subject completed all tests within 2 weeks.

\section{Measurements}

Before the experiments, their body composition was measured. Vigorous physical activity was restrained before each test session. The SCWT is a neuropsychological test used for clinical and experimental purposes. It was performed to evaluate the ability to suppress cognitive interference that occurs when processing different properties of the same stimulus si- 
multaneously. When the subject undertook the SCWT, they were asked to read aloud the words $(\mathrm{W})$, color symbols $(\mathrm{C})$, and color words (CW) arranged in random order for as long as 45 seconds. W read the words spoken in accordance with the order in which they were arranged in black, while C marked the 'XXXX' symbol with red, blue, and green and guided subjects to read words out in the order in which they were arranged. Finally, CW is a word in a color different from the meaning of the word (for example, the word 'blue' is printed in red), and the method is the same as the above method [24]. The interference score (IF) of the SCWT was calculated using the regression equation with $\mathrm{IG}=\mathrm{CW}-[(\mathrm{W} \times$ $\mathrm{C}) /(\mathrm{W}+\mathrm{C})][25]$. The total volume of sweat was calculated by weighing nude weight before and after the exercise bout after drying body surface.

\section{Statistical analysis}

Measured variables were expressed as mean \pm standard deviation (M \pm SD). The SPSS/PC Ver. 25 (IBM, NEW YORK, AMERICA) statistical

Table 2. Sweat volume in each condition

\begin{tabular}{lccccc}
\hline & Cold water & Warm water & No water & $F$ & $p$-values \\
\hline $\begin{array}{l}\text { Sweat } \\
\text { volume (g) }\end{array}$ & $470.7 \pm 141.7$ & $488.1 \pm 258.3$ & $416.7 \pm 142$ & 0.467 & 0.631 \\
\hline
\end{tabular}

Values are mean \pm SD.

Denotes significant difference: $p<.05$. package was used. One-way ANOVA and Scheffe were used to compare sweating verify the main effects. Two-way repeated measures of ANOVA were utilized for Skin temperature, RPE, SCWT comparing conditions. Scheffe was used as a post-hoc. The statistical significance level was set at $a=.05$.

\section{RESULTS}

\section{Construction of the prediction models}

The sweat volume in each condition was shown in Table 2. Sweat volume was the highest in warm water condition, but it was not statistically significant.

Skin temperature responses during exercise was shown in Table 3. No time and conditions interaction was noticed.

Ratings of perceived exertion was shown in Table 4, and no statistical differences were noticed between conditions.

The score of SCWT was shown in Table 5. The main effect of W in Stroop effect was statistically significant $(\mathrm{F}=29.726, p=.001)$, but no statistical significance was found in the interaction with water temperature. For the $\mathrm{C}$, the time effect was statistically significant $(\mathrm{F}=13.959, p=.003)$, but no interaction was significant. For the $\mathrm{CW}$, the time effect was obvious $(\mathrm{F}=10.236, p=.008)$, but no interaction with water temperature was

Table 3. Skin temperature responses during exercise

\begin{tabular}{|c|c|c|c|c|c|c|c|c|c|}
\hline & \multirow{2}{*}{ Cold water } & \multirow{2}{*}{ Warm water } & \multirow{2}{*}{ No water } & \multicolumn{2}{|c|}{ Water Temperature } & \multicolumn{2}{|c|}{ Time } & \multicolumn{2}{|c|}{ Interaction effect } \\
\hline & & & & $\mathrm{F}$ & $p$-values & $\mathrm{F}$ & $p$-values & $\mathrm{F}$ & $p$-values \\
\hline \multicolumn{10}{|c|}{ Triceps Brachii Muscle $\left({ }^{\circ} \mathrm{C}\right)$} \\
\hline $2 \min$ & $34.9 \pm 1.8$ & $35.2 \pm 1.0$ & $35.0 \pm 1.20$ & .255 & .696 & .792 & .475 & 1.106 & .352 \\
\hline $6 \min$ & $36.0 \pm 3.8$ & $35.1 \pm 1.4$ & $34.7 \pm 1.1$ & & & & & & \\
\hline $10 \mathrm{~min}$ & $35.9 \pm 5.7$ & $34.4 \pm 1.2$ & $34.2 \pm 1.1$ & & & & & & \\
\hline $14 \min$ & $33.9 \pm 1.9$ & $34.1 \pm 1.3$ & $35.0 \pm 2.7$ & & & & & & \\
\hline $18 \min$ & $34.6 \pm 1.3$ & $35.0 \pm 1.4$ & $35.0 \pm 0.8$ & & & & & & \\
\hline \multicolumn{10}{|c|}{ Pectoralis Major Muscle $\left({ }^{\circ} \mathrm{C}\right)$} \\
\hline $2 \min$ & $34.8 \pm 1.3$ & $35.7 \pm 1.0$ & $35.2 \pm 0.9$ & 1.945 & .167 & 4.015 & .044 & 1.371 & .265 \\
\hline $6 \mathrm{~min}$ & $34.4 \pm 0.8$ & $34.9 \pm 1.0$ & $34.9 \pm 0.9$ & & & & & & \\
\hline $10 \min$ & $34.6 \pm 0.9$ & $35.3 \pm 1.0$ & $35.1 \pm 0.9$ & & & & & & \\
\hline $14 \min$ & $34.9 \pm 0.9$ & $35.3 \pm 0.9$ & $35.5 \pm 0.8$ & & & & & & \\
\hline $18 \min$ & $35.3 \pm 0.9$ & $35.6 \pm 0.9$ & $35.7 \pm 0.8$ & & & & & & \\
\hline \multicolumn{10}{|c|}{ Quadriceps Femoris Musculus $\left({ }^{\circ} \mathrm{C}\right)$} \\
\hline $2 \min$ & $34.4 \pm 1.8$ & $35.8 \pm 1.3$ & $34.7 \pm 0.6$ & .700 & .507 & 1.406 & .267 & 1.824 & .148 \\
\hline $6 \min$ & $34.5 \pm 1.5$ & $35.6 \pm 1.3$ & $34.7 \pm 0.9$ & & & & & & \\
\hline $10 \min$ & $35.0 \pm 2.3$ & $35.4 \pm 1.7$ & $34.8 \pm 1.0$ & & & & & & \\
\hline $14 \min$ & $35.0 \pm 2.2$ & $35.1 \pm 2.4$ & $34.8 \pm 1.2$ & & & & & & \\
\hline $18 \min$ & $35.8 \pm 2.9$ & $35.3 \pm 1.4$ & $35.3 \pm 0.7$ & & & & & & \\
\hline
\end{tabular}

Values are mean \pm SD.

Denotes significant difference: $p<.05$. 
Table 4. Ratings of perceived exertion during exercise

\begin{tabular}{|c|c|c|c|c|c|c|c|c|c|}
\hline & \multirow{2}{*}{ Cold water } & \multirow{2}{*}{ Warm water } & \multirow{2}{*}{ No water } & \multicolumn{2}{|c|}{ Water Temperature } & \multicolumn{2}{|c|}{ Time } & \multicolumn{2}{|c|}{ Interaction Effect } \\
\hline & & & & $\mathrm{F}$ & $p$-values & $\mathrm{F}$ & $p$-values & $\mathrm{F}$ & $p$-values \\
\hline \multicolumn{10}{|l|}{ RPE } \\
\hline $6 \mathrm{~min}$ & $13.6 \pm 0.8$ & $13.8 \pm 1.0$ & $12.8 \pm 1.6$ & 2.950 & .073 & .015 & .942 & 2.021 & .139 \\
\hline $10 \min$ & $13.3 \pm 1.1$ & $13.9 \pm 1.0$ & $12.9 \pm 1.2$ & & & & & & \\
\hline $14 \mathrm{~min}$ & $13.3 \pm 1.3$ & $13.7 \pm 0.9$ & $13.1 \pm 1.3$ & & & & & & \\
\hline
\end{tabular}

Values are mean $\pm S D$.

RPE, Ratings of perceived exertion.

Denotes significant difference: $p<.05$.

Table 5. Stroop color and word test

\begin{tabular}{|c|c|c|c|c|c|c|c|c|c|}
\hline & \multirow{2}{*}{ Cold water } & \multirow{2}{*}{ Warm water } & \multirow{2}{*}{ No water } & \multicolumn{2}{|c|}{ Water Temperature } & \multicolumn{2}{|c|}{ Time } & \multicolumn{2}{|c|}{ Interaction effect } \\
\hline & & & & $\mathrm{F}$ & $p$-values & $\mathrm{F}$ & $p$-values & $\mathrm{F}$ & $p$-values \\
\hline \multicolumn{10}{|l|}{ W } \\
\hline Pre & $116.1 \pm 15.4$ & $112.8 \pm 15.2$ & $115.7 \pm 11.9$ & .071 & .930 & 29.726 & .001 & .762 & .48 \\
\hline Post & $120.7 \pm 15.5$ & $119.3 \pm 14.7$ & $119 \pm 13.9$ & & & & & & \\
\hline \multicolumn{10}{|l|}{ C } \\
\hline Pre & $88.6 \pm 19.9$ & $87.8 \pm 17.6$ & $91.6 \pm 12.0$ & .069 & .930 & 13.959 & .003 & 2.089 & .15 \\
\hline Post & $96.3 \pm 19.4$ & $92.4 \pm 21.1$ & $93.4 \pm 13.7$ & & & & & & \\
\hline \multicolumn{10}{|l|}{ CW } \\
\hline Pre & $74.7 \pm 22.1$ & $71.9 \pm 17.7$ & $71.2 \pm 12.9$ & .134 & .875 & 10.236 & .008 & .283 & .756 \\
\hline Post & $79.3 \pm 21.6$ & $79.4 \pm 18.0$ & $75.5 \pm 14.2$ & & & & & & \\
\hline \multicolumn{10}{|l|}{ IF } \\
\hline Pre & $24.7 \pm 15.1$ & $22.7 \pm 13.1$ & $20.2 \pm 10.2$ & .420 & .662 & 2.473 & .114 & .422 & .661 \\
\hline Post & $26.0 \pm 15.6$ & $27.6 \pm 9.60$ & $23.2 \pm 10.3$ & & & & & & \\
\hline
\end{tabular}

Values are mean $\pm S D$.

W, Word; C, Color; CW, Color+Word; IF, Interference score.

Denotes significant difference: $p<.05$.

noticed. IF did not show any statistically significance.

\section{DISCUSSION}

Exercise affects brain plasticity, leading to structural and functional changes that contribute to cognitive function [26]. In previous studies, exercise has helped reduce the risk of developing dementia, improved children's academic achievement, and enhanced memory and attention [27-30]. Genome analysis has shown attenuated stress-induced increases in miR-124, which is involved in nerve production and memory formation [31]. In addition, even in the same exercise, the cognitive response may be affected by various conditions, such as exercise intensity, time, subject, and environmental conditions [18,32].

Drinking water during exercise is important. Water accounts for the most part of human life maintaining homeostasis. especially during physically active or exposed to heat. In this case, more fluid consumption is necessary over the normal intake. Previous studies suggested a daily water requirement of 3.0-4.5 liter for those who participate in activities for more than 60 minutes a day, and up to 7 liter a day for highly active people. In addition, since physical activity in a hot environment requires more water, an additional water intake of 2-7 liters are needed over the daily requirement [33].

This study conducted the SCWT, a neuropsychological test, to investigate the effects of exercise on cognitive function even in a hot environment. In order to minimize the performance error of the subject, the preliminary practice time prior to the test was performed identically, and to minimize the learning effect of cognitive ability, different test papers were used for each test. The SCWT can assess cognitive functions. such as learning ability, attention, and thinking judged by the frontal lobe [34]. Therefore, the frontal lobe of the brain was considered to have a cognitive function and effect when exposed to the hot environment. As a result of the SCWT test scores, the results of W, C, and WC before and after exercise were significantly different in all conditions of water temperature and intake $(p<.001, p<.01$, and $p<.01$, respectively). Through this, 
high intensity exercise showed the cognitive improvement in a hot environment. This supports the findings of previous studies that cognitive improvement through exercise is more effective in high intensity exercise $[32,35]$ and that short term exercise affects cognitive function through aerobic exercise [36,37].

In the case of ingestion of warm and cold water and without drinking water, the difference was not statistically revealed, and the interactions were not observed. In this study, the temperature of drinking water and/ or without drinking water during exercise did not influence the cognitive ability. In previous studies, the cooling effects by water intake led to a decrease in skin temperature and the heat accumulation resulting an improvement of endurance performance in a hot environment [19]. Further discussion is needed on the increase of brain plasticity, water intake and temperature due to BDNF changes following aerobic performance for cognitive function. Previous studies measured the body core temperature while only skin temperature was measured in this study, which was the limitation of the study. For the better temperature measurements, the core, skin, and mean body temperature measures are warranted.

For the participants the exercise intensity was assumed to be a moderate intensity as shown in exertion ratings of 12-13. In the previous study, dehydration was affected by $2 \%$ of body weight before and after exercise [38]. However, in this experiment, the sweat loss was $470.7 \pm 141.7,488.1$ \pm 258.3 , and $416.7 \pm 142.0 \mathrm{~g}$ in cold water, warm water, and no water, respectively. These were only $0.6 \%$ of the average body weight loss, which seems to be insufficient for affecting cognitive ability. In other words, considering that the difference in the sweat loss according to the temperature and water intake did not show a significant difference, the temperature and water intake did not seem to have an influence on the appropriate level. Even in short-term exercise, children and the elderly are subjects who are more affected by cognition, but in the case of healthy young people, they are less affected by cognition and the influence on the cognitive ability will be lowered according to the fitness level of the subject [39]. By considering the subject's age or fitness level, the results may differ from those of this study.

\section{CONCLUSION}

The purpose of this study was to determine whether cold water consumption influenced cognitive response during a high intensity exercise in a hot environment. The subjects underwent the SCWT test, a cogni- tive test, after high-intensity exercise for 20 minutes at $39.2 \pm 2.1^{\circ} \mathrm{C}$ and $41.4 \pm 8.6 \%$ of humidity with cold water intake, warm water intake, and no intake. The results of W, C, and WC before and after exercise showed significant differences in all three different conditions. However, there was no difference in the cognitive scores in the three conditions. Exercise performance was found to improve cognitive function, but it was not confirmed whether cold water intake at a high temperature could improve cognitive function.

\section{CONFLICT OF INTEREST}

This study did not financial supported by any organizations.

\section{AUTHOR CONTRIBUTIONS}

Conceptualization, AR Jung; methodology, YB Lee; validation, DT Lee; formal analysis, YB Lee; investigation, JG Hwang; data curation, JG Hwang; writing-original draft preparation, YB Lee, SM Yun; writing-review and editing, HJ Lee; supervision, DT Lee; project administration, SM Yun

\section{ORCID}

$\begin{array}{ll}\text { Yunbin Lee } & \text { https://orcid.org/0000-0001-5927-1540 } \\ \text { Somi Yun } & \text { https://orcid.org/0000-0001-6659-9499 } \\ \text { Jaegu Hwang } & \text { https://orcid.org/0000-0002-2082-6294 } \\ \text { Heejin Lee } & \text { https://orcid.org/0000-0001-5194-0180 } \\ \text { Ah Reum Jung } & \text { https://orcid.org/0000-0002-5724-5186 } \\ \text { Dae Taek Lee } & \text { https://orcid.org/0000-0001-7025-8902 }\end{array}$

\section{REFERENCES}

1. Kenney WL, Wilmore JH, Costill DL. Physiology of sport and exercise. 5th ed., IL: Human Kinetics 2012;291-301.

2. Wendt D, Van Loon LJ, Lichtenbelt WDM. Thermoregulation during exercise in the heat. Sports Med. 2007;37(8):669-82.

3. Brothers RM, Wingo JE, Hubing KA, Crandall CG. The effects of reduced end-tidal carbon dioxide tension on cerebral blood flow during heat stress. J Physiol. 2009;587(15):3921-7.

4. Seo Y, Peacock CA, Gunstad J, Burns KJ, Pollock BS, et al. Do glucose containing beverages play a role in thermoregulation, thermal sensa- 
tion, and mood state? J Int Soc of Sports Nutr. 2014;11(1):24.

5. Choma CW, Sforzo GA, Keller BA. Impact of rapid weight loss on cognitive function in collegiate wrestlers. Med Sci Sports Exerc. 1998; 30(5):746-9.

6. Bandelow S, Maughan R, Shirreffs S, Ozgünen K, Kurdak S, et al. The effects of exercise, heat, cooling and rehydration strategies on cognitive function in football players. Scand J Med Sci Sports. 2010;20(3):14860

7. Adan A. Cognitive performance and dehydration. J Am Coll Nutr. 2012;31(2):71-8.

8. Hessemer V, Langusch D, Bruck LK, Bodeker RH, Breidenbach T. Effect of slightly lowered body temperatures on endurance performance in humans. J Appl Physiol Respir Environ Exerc Physiol. 1984;57(6): $1731-7$.

9. Lee DT, Haymes EM. Exercise duration and thermoregulatory responses after whole body precooling. J Appl Physiol. 1995;79(6):19716.

10. Olschewski H, Bruck K. Thermoregulatory, cardiovascular, and muscular factors related to exercise after precooling. J Appl Physiol. 1988; 64(2):803-11.

11. Schmidt V, Bruck K. Effect of a precooling maneuver on body temperature and exercise performance. J Appl Physiol Respir Environ Exerc Physiol. 1981;50(4):772-8.

12. Wegmann M, Faude O, Poppendieck W, Hecksteden A, Fröhlich M, et al. Pre-cooling and sports performance: a meta-analytical review. Sports Med. 2012;42(7):545-64.

13. Quinn T, Kim JH, Strauch A, Wu T, Powell J, et al. Physiological evaluation of cooling devices in conjunction with personal protective ensembles recommended for use in West Africa. Disaster Med Public Health Prep. 2017;11(5):573-9.

14. Booth J, Marino F, Ward JJ. Improved running performance in hot humid conditions following whole body precooling. Med Sci Sports Exerc. 1997;29(7):943-9.

15. Kay D, Taaffe DR, Marino FE. Whole-body pre-cooling and heat storage during self-paced cycling performance in warm humid conditions. J Sports Sci. 1999;17(12):937-44.

16. Oksa J, Ducharme MB, Rintamaki H. Combined effect of repetitive work and cold on muscle function and fatigue. J Appl Physiol. 2002; 92(1):354-61.

17. Imamura R, Rissanen S, Kinnunen M, Rintamaki, H. Manual performance in cold conditions while wearing NBC clothing. Ergon. 1998;
41(10):1421-32.

18. Mündel T, King J, Collacott E, Jones DA. Drink temperature influences fluid intake and endurance capacity in men during exercise in a hot, dry environment. Exp Physiol. 2006;91(5):925-33.

19. Lee JK, Shirreffs SM, Maughan RJ. Cold drink ingestion improves exercise endurance capacity in the heat. Med Sci Sports Exerc. 2008;40 (9):1637-44.

20. Wimer GS, Lamb DR, Sherman WM, Swanson SC. Temperature of ingested water and thermoregulation during moderate-intensity exercise. Can J Appl Physiol. 1997;22(5):479-93.

21. Masento NA, Golightly M, Field DT, Butler LT, Van Reekum CM. Effects of hydration status on cognitive performance and mood. Br J Nutr. 2014;111(10):1841-52.

22. Labbe D, Martin N, Le Coutre J, Hudry J. Impact of refreshing perception on mood, cognitive performance and brain oscillations: An exploratory study. Food Qual Prefer. 2011;22(1):92-100.

23. Bateman DN. Effects of meal temperature and volume on the emptying of liquid from the human stomach. J Physiol. 1982;331(1):461-7.

24. Scarpina F, Tagini S. The stroop color and word test. Front Psychol 2017;8:557

25. Golden CJ, Freshwater SM. Stroop color and word test. 1978. Chicago, IL: Stoelting.

26. Mandolesi L, Polverino A, Montuori S, Foti F, Ferraioli G, et al. Effects of physical exercise on cognitive functioning and wellbeing: biological and psychological benefits. Front Psychol. 2018;9:509.

27. Hollamby A, Davelaar EJ, Cadar D. Increased physical fitness is associated with higher executive functioning in people with dementia. Front Public Health. 2017;5:346.

28. Donnelly JE, Hillman CH, Castelli D, Etnier JL, Lee S, et al. Physical activity, fitness, cognitive function, and academic achievement in children: A systematic review. Med Sci Sports Exerc, 2016;48(6):1197-222.

29. Kramer AF, Hahn S, Cohen NJ, Banich MT, McAuley E, et al. Ageing, fitness and neurocognitive function. Nat. 1999;400(6743):418-9.

30. Lista I, Sorrentino G. Biological mechanisms of physical activity in preventing cognitive decline. Cell Mol Neurobiol. 2010;30(4):493-503.

31. Pan-Vazquez A, Rye N, Ameri M, McSparron B, Smallwood G, et al. Impact of voluntary exercise and housing conditions on hippocampal glucocorticoid receptor, miR-124 and anxiety. Mol Brain. 2015;8(1):40.

32. Hötting K, Schickert N, Kaiser J, Röder B, Schmidt-Kassow M. The effects of acute physical exercise on memory, peripheral BDNF, and cortisol in young adults. Neural Plast. 2016; 2016. https://doi.org/10. 
$1155 / 2016 / 6860573$.

33. Lee DT. Daily water requirement and exercise effects for adults. J Wellness. 2006;1(2):31-8.

34. Stuss DT, Floden D, Alexander MP, Levine B, Katz D. Stroop performance in focal lesion patients: dissociation of processes and frontal lobe lesion location. Neuropsychologia. 2001;39(8):771-86.

35. Brown BM, Peiffer JJ, Sohrabi HR, Mondal A, Gupta VB, et al. Intense physical activity is associated with cognitive performance in the elderly. Transl Psychiatry. 2012;2(11):e191.

36. Basso JC, Suzuki WA. The effects of acute exercise on mood, cognition, neurophysiology, and neurochemical pathways: a review. brain
Plast. 2017;2(2):127-52.

37. Ludyga S, Gerber M, Brand S, Holsboer-Trachsler E, Pühse U. Acute effects of moderate aerobic exercise on specific aspects of executive function in different age and fitness groups: a meta-analysis. Psychophysiology. 2016;53(11):1611-26.

38. Rodriguez NR, Di NM, Langley S. American college of sports medicine position stand. Nutrition and athletic performance. Med Sci Sports Exerc. 2009;41(3):709-31.

39. Chang YK, Labban JD, Gapin JI, Etnier JL. The effects of acute exercise on cognitive performance: a meta-analysis. Brain Res. 2012;1453: 87-101. 